\title{
Smoked cocaine in socially-depressed areas
}

\author{
Jordi Delas ${ }^{1,2,3^{*}}$, Elena Adán ${ }^{1}$, Olga Díaz ${ }^{1}$, Margarita Aguas ${ }^{3}$, Montserrat Pons $^{3}$, Ricardo Fuertes ${ }^{1}$
}

\begin{abstract}
Background: The main objectives of this study are to describe the smoked cocaine user's profile in sociallydepressed areas and their needs from a harm-reduction perspective, to investigate their use of smoking crack and compare the acute effects between injecting and smoking consumption.

Methods: The study took place in SAPS, Barcelona, Spain. Two focus group sessions were undertaken with a total of 8 drug users. Secondly, the 8 participants answered a structured questionnaire and in the course of the sessions, as a snowball activity, were trained to survey 6 other crack smokers.

Results: We obtained 56 questionnaires. The majority of participants were from non-European Community countries (62.69\%), $70.2 \%$ of participants referred to sharing the smoking equipment. The most frequent symptoms reported during smoked cocaine were mydriasis (83.33\%)), perspiration (72.92\%) and compulsive object search (70.83\%) During the group sessions, participants said that smoked cocaine is much more addictive than injected cocaine and causes more anxiety. Participants also reported the difficulty of changing from injected use to smoked use, due to the larger amount of cocaine needed to reach the same effects as when having injected.

Conclusions: We can conclude that the research, focused on achieving greater knowledge of the smoked cocaine user's profile, their usage of smoking crack, consumption patterns and acute effects, should be incorporated into substance misuse interventions.
\end{abstract}

\section{Background}

SAPS Creu Roja is a harm-reduction center located in Ciutat Vella, one of the main areas of drug use and dealing in Barcelona, Spain. It provides health and social care, and psychological and legal assistance to drug users in socially-deprived situations. $86 \%$ of the people attended to are men, $13 \%$ women and $1 \%$ transsexuals, and $85 \%$ are homeless. Opened in Barcelona in 1993, it is located in one of the main drug use and dealing areas in Barcelona. Until the end of December 2008 the center received 58,978 visits and since the beginning 11,381 different people have been registered. In 2008, 811 people were attended to for the first time and on average 154 different people visit the service per day. During 2008 the index of syringes recovered was 0.35 , with 90,488 syringes delivered and 32,104 recovered. The human resources are 1 coordinator, 4 nurses, 6 social educators, 1 medical internist, 1 lawyer and 1 psychologist. Condoms, new needles and smoking equipment are also offered for free.

\footnotetext{
* Correspondence: jdelas@ub.edu

'SAPS Creu Roja. (Av. Drassanes 13-15), Barcelona 08001, Spain

Full list of author information is available at the end of the article
}

In 2003, a drug consumption room for injected use, supervised by healthcare professionals, was added to the initial needle exchange program. This drug consumption room allows the professionals to directly observe the injected heroin and cocaine consumption and their acute effects [1] and act in emergency situations.

Like many harm-reduction programs in the southern Europe, SAPS was primarily focused on injected drug use [2]. The change in the method of consumption from injecting to smoking is recommended to reduce the blood-borne infectious diseases such HIV, Hepatitis B and $C$, and other diseases directly related to injection, such as abscess, phlebitis or thrombosis. It is also possible to reduce mortality related to acute reactions to intravenous consumption [3].

However, merely suggesting is not sufficient to promote this change of method of consumption from injecting to smoking. We must have an in-depth knowledge of the specific characteristics of smoked use and that the harm-reduction centres can provide the chance to smoke instead of injecting. In many cities crack smokers have been largely ignored in the development and implementation of harm-reduction programmes. [4,5]
C Biomed Central

C 2010 Delas et al; licensee BioMed Central Ltd. This is an Open Access article distributed under the terms of the Creative Commons Attribution License (http://creativecommons.org/licenses/by/2.0), which permits unrestricted use, distribution, and reproduction in any medium, provided the original work is properly cited. 
The main objectives of this study are to describe the smoked cocaine user's profile in socially-depressed areas and their needs from a harm-reduction perspective, to investigate their use of smoking crack and consumption patterns and compare the acute effects between injecting and smoking consumption.

\section{Methods}

The study took place in SAPS Creu Roja, Barcelona, Spain and was included in the context of the workshops organized annually by the Program on Substance Abuse of the Ministry of Health of Catalonia, based on snowball activities [6].

A twofold methodology was used:

\section{Focus groups}

On the one hand, two focus group sessions of two hours each were undertaken with a total of 8 drug users. Participants were recruited in January 2008, firstly from those who attended our centre, according to the following criteria: they have smoked cocaine and have minimum language skills in speaking, reading and writing. The sessions were managed by three staff members (two nurses and one social worker) following a semi-structured script. The lines of discussion were the health risk of smoking drugs, mainly using crack, smoking equipment and the transmission of infectious diseases. Participants were asked to make pipes with the material they use and discuss its specific risks. Also discussed was a comparison of both ways of consumption, injecting and smoking, by presenting the most frequent effects observed in our drug-consumption room. ${ }^{1}$ Also discussed was the acceptance and need for harm-reduction interventions such as safe smoking equipment and drug consumption rooms for smoking users. In this focus group, the data was collected through field notes of the three staff members, who at the end of the session compared their notes.

\section{Structured questionnaires}

Secondly, the 8 participants of the focus groups answered a structured questionnaire and in the course of the sessions, as a snowball activity, were trained to survey 6 other crack smokers who were not clients of our centre. The questionnaire includes some questions in the first part that always appear in the enquiries organized annually by the Program on Substance Abuse of the Ministry of Health of Catalonia, based on snowball sampling. A second specific group of questions was designed specifically for this piece of research, taking into account current socio-demographic data, health information (respiratory diseases and treatment), history of drug use, characteristics of smoked cocaine (material for cooking from hydrochloride to base cocaine, kinds of handmade pipes, patterns of use) and about their acceptance of the possibility of attending a drug consumption room for smoking. The last part of the questionnaire was a list of the effects of injected cocaine observed in our drug consumption room ${ }^{1}$ and participants were asked to answer "yes or no" if they notice when smoking.

Descriptive statistics were used to determine variable frequencies for all items of the questionnaire.

\section{Commitment contract and informed consent}

Confidentiality measures: the focus group's participants signed an informed consent authorising the researchers to use their data. They also signed a commitment contract through which they were going to respect the confidentiality of their respondents.

\section{Control of quality and validity of questionnaires}

Within the interviewers' training, communication skills were assessed using a standard questionnaire designed by the Program on Substance Abuse of the Ministry of Health of Catalonia. Participants were asked for difficulties and possible obstacles to doing the survey. These were also assessed once after the questionnaires were completed and returned to the researchers.

The 8 main participants were paid $€ 40$ for their participation in the sessions and $€ 10$ more for each survey administered by them. All participants were guaranteed that any information they provided would remain strictly anonymous and confidential. In the same contract mentioned above, the participant was informed that their active participation, and the quality and validity of the data given to the researchers was essential to be paid for it. These aspects were evaluated by the research team analysing the questionnaires.

The study was submitted to the Program on Substance Abuse of the Ministry of Health of Catalonia where it was assessed in terms of ethics and validity. Data was processed using the SPSS 15 statistical program.

\section{Results}

\section{Structured questionnaire}

We obtained 56 questionnaires, 8 from participants in the group sessions and 48 from the snowball sample.

1. Socio-demographic data showed that $80 \%$ were male $(n=45)$ with an average of age of 32.6 (range from 19 to 63 years old). The majority of participants were from non-European Community countries (62.69\%). $45.5 \%$ stated they did not have identity documents and $38.2 \%$ did not have a health card.

Responding to where they live, 22 (39.3\%) were sleeping rough and $14(25 \%)$ were squatters. Regarding their main financial income, $46.3 \%$ stated petty crime, $7.40 \%$ 
Table 1 Interviews: Socio-demographic data

\begin{tabular}{|c|c|c|c|c|c|c|c|}
\hline \multirow{3}{*}{$\begin{array}{l}\text { Gender } \\
\text { Average } \\
\text { Country }\end{array}$} & \multirow[t]{2}{*}{ Men: 45 (80\%) } & \multicolumn{6}{|c|}{ Women: 11 (20\%) } \\
\hline & & \multicolumn{6}{|c|}{$32.68 \pm 3.74$ years old (confidence interval 95\%) (range of: 19 to 63 years old) } \\
\hline \multirow{3}{*}{\multicolumn{2}{|c|}{ Country of origin }} & Spa & & & 11 & & $19.6 \%$ \\
\hline & & Oth & ean Cor & countries: & 21 & & $42.8 \%$ \\
\hline & & Nor & an Comi & ountries: & 24 & & $37.6 \%$ \\
\hline \multicolumn{4}{|c|}{ Average time living in Spain (not born in Spain) } & \multicolumn{4}{|c|}{6.13 years (range of $0.16-28$ years) } \\
\hline \multicolumn{4}{|c|}{ Identity Document } & YES: 30 (54.4\%) & NO: 25 (45.5\%) & \multirow{2}{*}{\multicolumn{2}{|c|}{ MISSING: 1 (1.8\%) }} \\
\hline \multicolumn{4}{|c|}{ Health card } & YES: 29 (51.8\%) & NO: $27(48.2 \%)$ & & \\
\hline \multicolumn{4}{|c|}{ Using soup kitchens and charity settings } & $1733.30 \%$ & & & \\
\hline \multirow[t]{5}{*}{ Housing } & Sleeping Rough & 22 & $39.3 \%$ & Main Income & Petty crime & 25 & $46.3 \%$ \\
\hline & Squatters & 14 & $25 \%$ & & Financial aid & 4 & $7.4 \%$ \\
\hline & Own house & 8 & $14.3 \%$ & & Temporary job & 2 & $3.7 \%$ \\
\hline & Hostel & 3 & $5.4 \%$ & & Missing & 2 & $3,6 \%$ \\
\hline & Others & 9 & $16 \%$ & & Others & 22 & $42.7 \%$ \\
\hline
\end{tabular}

were receiving financial benefits and only $3.70 \%$ had a temporary job (Table 1).

Relating to drug use, at the time of the interview only one person was in withdrawal and 5 were not current crack cocaine smokers. Of those who were cocaine smokers in that moment $(\mathrm{n}=42), 19(45.23 \%)$ only smoked and $23(54.76 \%)$ combined smoking with snorting or injecting. Of those 42 current cocaine smokers, 39 (92.85\%) were using this drug in combination with some kind of depressants such as methadone, heroine, benzodiazepines or alcohol.

When participants were asked about some characteristics of smoking crack cocaine, $76.8 \%$ responded that they preferred to use ammonia to convert the cocaine hydrochloride into cocaine base or crack, compared to $41.1 \%$ who preferred sodium bicarbonate. The paraphernalia used were handmade pipes in $87.5 \%$ of responses, $76.4 \%$ usually smoked with someone else and $70.2 \%$ of participants referred to sharing the smoking equipment.

3) Regarding the place of consumption, $48.10 \%$ smoked cocaine in public places, $29.60 \%$ in private places, whereas $22.20 \%$ referred to doing it in both (Table 2). 44.4\% of users interviewed knew about existing consumption rooms for smokers in other countries. $72.7 \%$ considered them as necessary and $65.1 \%$ would use them if they were available (Table 3 ).

4) The most frequent symptoms reported during smoked cocaine were mydriasis $(83.33 \%)$ ), perspiration (72.92\%) and compulsive object search (70.83\%) (Table 3).

\section{Focus group}

During the group sessions we were able to collect information from the discussion sessions on issues such as: substances, their effects and the method of smoking crack cocaine. We also asked about comparing smoked and injected use.
Participants said that smoked cocaine is much more addictive than injected cocaine and causes more anxiety. Some of them find this method of consumption unpleasant.

Talking about the health risks of smoking crack, participants were sceptical about the idea that infectious diseases such as HIV or HCV can be transmitted through pipes, so they usually share smoking equipment. Nevertheless many users were more familiar with other diseases such as tuberculosis or other pulmonary diseases. Other problems that they easily related to smoking crack were cuts and burns on hands and lips due to inadequate material for making the pipes.

Participants were asked to make pipes in a session using material that they usually have. The most common objects were plastic water or methadone bottles. The top is replaced by a piece of foil fixed with an elastic (usually a part of a latex glove or a condom), which is perforated with a needle. A hole is made in the side of the bottle, usually burning the plastic with a cigarette, where a piece of a syringe is placed and used as a stem. Other materials used are plastic glasses and medical inhalers. Smoking on foil is not very common when using crack, participants explaining that it is used when smoking heroin or both substances at the same time.

When referring to the substances used to convert the cocaine hydrochloride to cocaine base participants explained that using ammonia is easier than sodium bicarbonate. It consists of mixing the ammonia with powdered cocaine, then an oily drop is obtained that can be separated and when dry becomes a rock. This makes it easier when the consumption is in the street or when the user has not too much experience. Another reason to use ammonia instead of sodium bicarbonate was the flavour it has when cocaine is smoked. Smoking cocaine, like injected cocaine, is usually combined with the use of depressants such as heroin, benzodiazepines 
Table 2 Interviews: Drug use data

\begin{tabular}{|c|c|c|c|c|c|}
\hline & Cocaine & Heroine & Alcohol & Benzodiazepines & Cannabis \\
\hline \multirow[t]{2}{*}{ Drug use } & $47(83.9 \%)$ & $44(78.6 \%)$ & $30(53.6 \%)$ & $15(26.8 \%)$ & $35(62.5 \%)$ \\
\hline & \multicolumn{3}{|c|}{ Cocaine, heroine, alcohol, benzodiazepines and cannabis } & 6 & $10.7 \%$ \\
\hline \multirow{4}{*}{$\begin{array}{l}\text { Drugs alone or } \\
\text { combined }\end{array}$} & \multicolumn{3}{|c|}{ Cocaine, heroine, alcohol and benzodiazepines } & 9 & $16.1 \%$ \\
\hline & \multicolumn{3}{|c|}{ Cocaine, heroine and alcohol. } & 26 & $46.4 \%$ \\
\hline & \multicolumn{3}{|c|}{ Cocaine and heroine } & 40 & $71.4 \%$ \\
\hline & \multicolumn{3}{|c|}{ Cocaine } & 47 & $83.9 \%$ \\
\hline \multicolumn{6}{|l|}{ SMOKED COCAINE } \\
\hline Crack cocaine preparation & \multicolumn{2}{|c|}{ Ammonia 43 (76.8\%) } & \multicolumn{3}{|l|}{ Baking soda 23 (41.1\%) } \\
\hline Smoking equipment & \multicolumn{2}{|c|}{ Bottle Pipe 49 (87.5\%) } & \multicolumn{2}{|c|}{ Foil $25(44.6 \%)$} & \\
\hline Smoke pipes & \multicolumn{2}{|c|}{ Yes $47(83,9)$} & \multicolumn{3}{|c|}{ Share pipes (\% of those who smoke pipes) 33 (70.2\%) } \\
\hline Alone or with someone else & \multicolumn{2}{|c|}{ Alone 7 (12.7\%) } & Someone else 42 (76.4\%) & \multirow[t]{2}{*}{ Both $6(10.9 \%)$} & Missing 1 \\
\hline Where do they smoke? & Public pla & $48.10 \%)$ & Private place 16 (29.60\%) & & At home $16(29,6)$ \\
\hline \multicolumn{6}{|c|}{ Daily average dose (grams per day) } \\
\hline $\mathbf{N}$ & & $\%$ & Snorted & Smoked & Injected \\
\hline 18 & & 2.14 & $1.32 \mathrm{~g} /$ day & 3.4 g/day & -—- \\
\hline 8 & & 4.28 & $1.29 \mathrm{~g} /$ day & -—— & $2.58 \mathrm{~g} /$ day \\
\hline 14 & & 5.00 & - - & $4.45 \mathrm{~g} /$ day & $2.02 \mathrm{~g} /$ day \\
\hline
\end{tabular}

or alcohol, which reduces the strong effects of cocaine. Those participants using other methods of consumption described smoked cocaine as more compulsive as it generates more anxiety, and some of them even found it unpleasant.

They explained that the most frequently combined methods of consuming are to snort and smoke, but the injected use is not usually combined with any other method due to the larger amount needed to reach the same effects. Participants also reported the difficulty of

Table 3 Cocaine effects

\begin{tabular}{lcc}
\hline EFFECTS & \% INJECTED & \% SMOKED \\
\hline Mydriasis (pupil dilation) & 29.8 & 83.33 \\
Perspiration & 35.1 & 72.92 \\
Object Search & 14.9 & 70.83 \\
Verbosity & 49.4 & 66.67 \\
Tachypnea (respiratory rate rise) & 1.8 & 64.58 \\
Compulsive cleaning and tidying & 1.8 & 62.5 \\
Tactile hallucinations & 3.0 & 60.42 \\
Agitation & 9.5 & 58.33 \\
Auditory hallucinations & 8.9 & 58.33 \\
Salivation & 14.9 & 56.25 \\
Persecution complex & 3.6 & 54.17 \\
Confusion & 7.1 & 52.08 \\
Repeated Movements & 9.5 & 50 \\
Tachycardia & 8.3 & 50 \\
Chest pain & 0 & 45.83 \\
Visual hallucinations & 13.7 & 35.42 \\
Temporary paralysis & 5.4 & 33.33 \\
Convulsions & 0 & 31.25 \\
Delirium & 1.2 & 29.17 \\
\hline
\end{tabular}

changing from injected use to smoked use, due to the larger amount of cocaine needed to reach the same effects as when having injected. [7] Due to the cost and availability of crack cocaine, they reported preferring to buy powdered cocaine and cook it by themselves to making crack cocaine (in their environment $50 \mathrm{mg}$ of cocaine costs $€ 5$, whereas $200 \mathrm{mg}$ of powdered cocaine costs $€ 10)$. The majority reported sharing pipes as they use them to smoke with friends or acquaintances, but not with strangers.

Their opinion about smoking rooms is controversial (Table 4). They said that the acute effects of smoked cocaine, such as agitation and aggressive behaviour, would require a lot of control from professionals, as well as protection and security. They mentioned the existence of what are called "Crack Houses", where drug dealers and drug users buy, sell, produce, and use illegal drugs, including, but not limited to, crack cocaine. However, these are found in some places in Europe and the USA, but not in Spain.

\section{Discussion}

Harm-reduction brings hidden marginalised drug users in contact with social and health services. Crack smoking involves particular risks and harms, which

Table 4 Interviews: Their opinion about drug consumption rooms

\begin{tabular}{lll}
\hline DRUG CONSUMPTION ROOMS & $\mathbf{n}$ & $\%$ \\
\hline Know about them & 24 & $44.4 \%$ \\
Consider them needed & 40 & $72.7 \%$ \\
They would use them & 28 & $65.1 \%$ \\
\hline
\end{tabular}


underlines the need for targeted interventions [8]. In this study, the snowballing methodology enabled us to be in contact with cocaine smokers who were not attending the harm-reduction centres and provided us with very important information [9]. The primary goal of most harm-reduction approaches is to meet individuals "where they are at" [10]. Despite this method being known to have limitations and bias, in hidden populations it is currently still one of the slightly better methods [6].

Enquiries in which external pollsters to the researcher group are needed represent a weak point. However, in illegal areas of study it is even more complicated. Some groups' researchers use a snowballing method characterized by assigning names to people who will be contacted. It was also complicated in this study because the aim was to interview people who do not have contact with our service [6]. This kind of survey is not practical for researching strictly defined questions or attributing causal relations. But when the aim is to share information based on scientific arguments about drug users who smoke cocaine, this methodology continues to have an important role. It involves sharing hot and cold information between reality and scientific concepts. The 8 main participants were paid. This provided an incentive to them to complete the surveys and also gave them recognition or respect for their role and skills.

The analysis of demographic characteristics shows that the participants of our study are in a socially-deprived situation according to one of our objectives, to find out more about their condition and to represent the current profile of illegal drug users: men, foreigners, without access to basic needs (lodging, food, hygiene and healthcare) $[11,12]$.

Survey results show that $48.10 \%$ smoke in public. This may have a negative impact on the community, and can also aggravate the risk for users, due to the difficulties in preparing the substance properly and environmental conditions of consumption [13,14]. Implementation of specific harm-reduction strategies for crack smokers are necessary among this population, focusing on social and health care as well as strategies directly related to safety, including on-site preparation of the cocaine to be smoked.

Results show that the use of pipes is important for $70 \%$ and in this case the rate of shared pipes is $70.2 \%$. Supervised inhalation and smoking sites could increase the availability of new pipes, mouthpieces for pipes and education for safer consumption. Smoking of crack cocaine was found to be an independent risk factor for HIV seroconversion among people who injected drugs [15]. The authors suggest that wounds in and around the mouth from using metal or glass pipes may make people who smoke crack cocaine more vulnerable to
HIV transmission during activities such as oral sex or sharing of crack pipes. As a part of a comprehensive HIV prevention strategy, harm-reduction programs should address the unique needs of people who smoke crack cocaine [16].

The change by cocaine injectors to smoking crack cocaine may be easier for those who have smoked before, and could be more bearable if they have smoking equipment available ${ }^{4}$ and a safe and private place to smoke.

More effects were recalled through the discussion sessions when compared with those we observed in the drug-injecting room, perhaps due to the users' expression of their own personal experience, which cannot be discovered entirely through observation only $[17,18]$.

As in the case of injected use, drug-taking rooms make the direct observation of effects possible, which as participants mentioned, could be greater than when cocaine is injected. This fact can be related to the differences in cocaine metabolism in these different ways of administrating the drug [19].

\section{Conclusions}

We can conclude that the research, focused on achieving greater knowledge of the smoked cocaine user's profile, their usage of smoking crack, consumption patterns and acute effects, should be incorporated into substance misuse interventions, disease prevention and health promotion policy in order to provide a better response $[20,21]$.

\section{Acknowledgements}

We thank Steve Cedar who provided medical writing services and Vicerectorat de Política Docent i Científica Universitat de Barcelona for its contribution to manuscript publication.

\section{Author details}

'SAPS Creu Roja. (Av. Drassanes 13-15), Barcelona 08001, Spain.

2Departamento de Medicina, Universitat de Barcelona. (Casanova, 143), Barcelona 08036, Spain. ${ }^{3}$ Hospital Universitari del Sagrat Cor. (Viladomat, 288), Barcelona 08029, Spain.

\section{Authors' contributions}

JD, EA. OD and RF designed the study and wrote the protocol. MA and MP undertook the statistical analysis. JD and EA wrote the first draft of the manuscript. All authors contributed to and have approved the final manuscript.

\section{Competing interests}

The authors declare that they have no competing interests

Received: 4 August 2010 Accepted: 9 November 2010

Published: 9 November 2010

\section{References}

1. Delás J, Priore AG, Pigem A, Aguas M: Post cocaine intravenous syndrome described from the observation in a drug consumption supervised room. Med Clin (Barc) 2008, 130:35-6.

2. Andrés $M$, Delás J: Thoughts about future of non legal drugs related injuries reduction in the South of Europe. Med Clin (Barc) 2005, 125:700-2. 
3. Fischer B, Manzoni P, Rehm J: Comparing Injecting and Non-Injecting Illicit Opioid Users in a Multisite Canadian Sample (OPICAN Cohort). Eur Addict Res 2006, 12:230-239.

4. Boyd S, Johnson JL, Moffat B: Opportunities to learn and barriers to change: crack cocaine use in the Downtown Eastside of Vancouver. Harm Reduct 2008, 17(5):34.

5. Leonard L, DeRubeis E, Pelude L, Medd E, Birkett N, Seto J: "I inject less as I have easier access to pipes": injecting, and sharing of crack-smoking materials, decline as safer crack-smoking resources are distributed. Int $J$ Drug Policy 19:255-264.

6. Eland-Goossensen MA, Van De Goor LAM, Vollemans EC, Hendriks VM, Garretsen HFL: Snowball sampling applied to Opiate addicts outside the Treatment system. Addict Res Theory 1997, 5:317-330.

7. Nunes $\mathrm{CL}$, Andrade T, Galvão-Castro B, Bastos Fl, Reingold A: Assessing risk behaviour and prevalence of sexually transmitted and blood-borne infections among female crack cocaine users in Salvador-Bahia, Brazil. Braz J Infect Dis 2007, 11:561-6.

8. Haydon E, Fischer B: Crack use as a public health problem in Canada: call for an evaluation of 'safer crack use kits'. Can J Public Health 2005, 96:185-188.

9. Heller DI, Paone D, Siegler A, Karpati A: The syringe gap: an assessment of sterile syringe need and acquisition among syringe exchange program participants in New York City. Harm Reduct J 2009, 6:1.

10. Marlatt GA, Witkiewitz K: Update on harm-reduction policy and intervention research. Annu Rev Clin Psychol 2010, 591-606.

11. Torralba L, Brugal MT, Villalbí JR, Tortosa MT, Toribio A, Valverde JL: Mortality due to acute adverse drug reactions: opiates and cocaine in Barcelona, 1989-93. Addiction 1996, 91:419-426.

12. Brugal $M T$, Barrio $G$, De $L F$, Regidor $E$, Royuela $L$, Suelves JM: Factors associated with non-fatal heroin overdose: assessing the effect of frequency and route of heroin administration. Addiction 2002, 97:319-27.

13. Wood E, Kerr T, Small W, Li K, Marsh DC, Montaner JS, Tyndall MW: Changes in public order after the opening of a medically supervised safer injecting facility for illicit injection drug users. CMAJ 2004 171:731-734.

14. Shannon K, Ishida T, Morgan R, Bear A, Oleson M, Kerr T, Tyndall MW: Potential community and public health impacts of medically supervised safer smoking facilities for crack cocaine users. Harm Reduction Journal 2006, 3:1.

15. DeBeck K, Kerr T, Li K, Fischer B, Buxton J, Montaner J, Wood E: Smoking of crack cocaine as a risk factor for HIV infection among people who use injection drugs. CMAJ 2009, 181:585-9.

16. Celentano D, Sherman : The changing landscape of crack cocaine use and HIV infection. SG CMAJ 2009, 181:571-2.

17. Reed SC, Haney M, Evans SM, Vadhan NP, Rubin E, Foltin RW: Cardiovascular and subjective effects of repeated smoked cocaine administration in experienced cocaine users. Drug Alcohol Depend 2009, 102:102-7.

18. Foltin RW, Ward AS, Haney M, Hart CL, Collins ED: The effects of escalating doses of smoked cocaine in humans. Drug Alcohol Depend 2003, 70:149-157.

19. Hatsukami DK, Fischman MW: Crack cocaine and cocaine hydrochloride. Are the differences myth or reality? JAMA 1996, 276:1580-1588.

20. Malchy L, Bungay V, Johnson J: Documenting practices and perceptions of 'safer' crack use: a Canadian pilot study. Int J Drug Policy 2008, 19:339-41.

21. Hedrich D: European report on drug consumption rooms. European Monitoring Centre for Drugs and Drug Addiction. Luxemburg 2004.

doi:10.1186/1477-7517-7-27

Cite this article as: Delas et al: Smoked cocaine in socially-depressed areas. Harm Reduction Journal 2010 7:27.

\section{Submit your next manuscript to BioMed Central and take full advantage of:}

- Convenient online submission

- Thorough peer review

- No space constraints or color figure charges

- Immediate publication on acceptance

- Inclusion in PubMed, CAS, Scopus and Google Scholar

- Research which is freely available for redistribution

Submit your manuscript at www.biomedcentral.com/submit 